\title{
PARA LEER A NIETZSCHE COMO NIETZSCHEANO
}

Reading Nietzsche as a Nietzschean

\author{
Scarlett Marton
}

Universidad de São Paulo

RESUMEN: En este artículo intentamos hacer una evaluación crítica de la edición española de las Obras completas, de los Fragmentos póstumos y de la Correspondencia de Nietzsche. Examinaremos dos aspectos en particular, a saber: el trabajo de traducción y la elaboración del aparato crítico.

Palabras clave: edición - traducción - filología - historia - contextualización

ABSTRACT: In this article, we aim at making a critical evaluation of the Spanish edition of Nietzsche's Complete Works, Posthumous Fragments and Correspondence. We intend to examine particularly two aspects: the translation which has been made and the critical apparatus which has been elaborated.

Keywords: edition - translation - philology - history - contextualization

Es sabido que, en lo que respecta tanto a las ciencias humanas como a la filosofía, los objetos de conocimiento no están simplemente dados; hay que construirlos ${ }^{1}$. Cuando de lo que se trata es de otorgar a Nietzsche su legitimidad filosófica, no podemos pasar por alto las herramientas de trabajo. Y lo primero que se exige es el acceso a ediciones rigurosas de sus escritos.

Está fuera de duda que la edición crítica de las obras completas de Nietzsche organizada por Giorgio Colli y Mazzino Montinari ha sido de gran importancia para los estudios nietzscheanos. Como resultado de un largo trabajo, que se realizó de un modo extremadamente riguroso a lo largo de los años, se ha convertido en una herramienta indispensable para la investigación internacional sobre la filosofía nietzscheana. Dicha edición crítica presenta unas cualidades indiscutibles: ha permitido

1. Al ocuparse de la constitución de los campos del saber en Francia, Bourdieu ha mostrado perfectamente que una obra no se convierte en un objeto de conocimiento hasta que es considerada como tal por parte de lectores cualificados, que en general se encuentran implicados en las redes de poder de las universidades y de los centros de investigación. Cf. P. Bourdieu, Les règles de l'art: Genèse et structure du champ littéraire, Paris: Seuil, 1992, en particular los capítulos «L'émergence d'une structure dualiste» $\mathrm{y}$ «La marché des biens symboliques». 
el acceso a los investigadores al conjunto de los escritos del autor de Zaratustra; ha intentado restaurar sus textos según los manuscritos originales y organizarlos según el orden cronológico de su surgimiento; ha puesto en duda la existencia del libro titulado La voluntad de poder; se ha comprometido a depurar la obra publicada y las notas inéditas de las distorsiones y falsificaciones que habían sufrido; ha proporcionado un importante aparato histórico-filológico de valor incalculable.

Bien recibida en España en los años setenta, la edición Colli-Montinari despertó el interés por la vida y el pensamiento de Nietzsche entre los ambientes universitarios. Más adelante, al organizar una versión electrónica de dicha edición, el grupo de investigación Hyper Nietzsche dirigido por Paolo D'Iorio incorporó las correcciones filológicas establecidas en los volúmenes complementarios (Nachberichte) $^{2}$.

Ha sido precisamente a partir de esta edición que los investigadores reunidos en torno a SEDEN decidieron iniciar la edición española de las Obras completas y de los Fragmentos póstumos de Friedrich Nietzsche ${ }^{3}$. Con el fin de dar un acceso a sus textos a todos aquellos que quisieran dedicarse a su lectura y su comprensión, se lanzaron a esta empresa bajo la dirección de Diego Sánchez Meca. En el primer volumen de las Obras completas, Sánchez Meca delinea los tres objetivos principales de este trabajo, a saber: realizar una traducción fiel de los textos del filósofo, elaborar un aparato crítico actualizado e incluir introducciones a los escritos para contextualizarlas ${ }^{4}$.

De entre los numerosos aspectos de esta extraordinaria empresa, hay uno que nos llama rápidamente la atención: el trabajo de traducción. Debe destacarse que ha sido realizada por un grupo de investigadores expertos en la filosofía nietzscheana y que estos investigadores se encuentran en permanente diálogo entre sí. Estos dos puntos marcan la diferencia de la edición española, si la comparamos con los textos nietzscheanos publicados en otros países, por ejemplo Brasil o Francia.

En 1900, consciente de la difusión de las ideas de Nietzsche en Francia, André Gide había escrito: «La influencia de Nietzsche ha precedido, en nuestro país, a la aparición de su obra ${ }^{5}$. En las Cartas a Ángela subraya que, gracias a la lentitud de la publicación de las traducciones al francés de sus libros, estas se convirtieron en muy indispensables. Más de ciento veinte años después de haberse escrito, las palabras de Gide podrían aplicarse perfectamente para describir la situación brasileña: a día de hoy, los textos nietzscheanos no han sido todavía traducidos en su integridad al portugués.

En Brasil, el autor de Zaratustra se ha hecho famoso antes de incluso de haber sido conocido. Por otro lado, en Francia la traducción de las Euvres philosophiques complètes de Nietzsche, publicadas en la casa Gallimard ${ }^{6}$, ha sido confiada a

2. Se trata de la eKGWB, accesible en la web http://www.nietzschesource.org, y organizada a partir de los Sämtliche Werke. Kritische Studienausgabe (KSA), 15 vols., Berlin: Walter de Gruyter, 1967-1977, y de Nietzsche Werke. Kritische Gesamtausgabe (KGW), 40 vols., en 9 secciones, Berlin: Walter de Gruyter, 1967 ss.

3. Sobre este tema, remitimos al texto de M. Parmeggiani, M. y F. Fava, «Nietzsche na Espanha», en S. Marton (ed.), Nietzsche em chave hispãnica, São Paulo: Loyola, 2015, pp. 11-60.

4. Cf. D. Sánchez Meca, «Criterios de esta edición», OC I, p. 56.

5. A. Gide, Lettres à Angèle, en Euvres complètes, Paris: NRF, 1936, p. 229.

6. F. Nietzsche, Euvres philosophiques complètes, 14 vols., Paris: Gallimard, 1968 ss. 
diversos traductores que, salvo algunas excepciones, no se dedicaban de manera particular a la filosofía nietzscheana y que, además, tampoco han dialogado entre sí. En ambos casos, quienes han proporcionado el trabajo de traducción no han aprovechado la ocasión para ponerse de acuerdo con respecto a las mejores opciones para verter en portugués o en francés los principales conceptos en los escritos de Nietzsche. La ausencia de un canon ha favorecido, por tanto, la aparición de las más diversas interpretaciones sobre su pensamiento.

En cambio, los objetivos que han orientado la edición de las Obras completas y de los Fragmentos póstumos de Nietzsche publicados en España son completamente distintos. Los investigadores que durante este tiempo han trabajado en estrecha colaboración se han reunido alrededor de un proyecto que, ante todo, aspira a verter al español el sentido de los textos originales del modo más preciso posible. Esto ha llevado a un trabajo a lo largo de los años en el que han sido plenamente conscientes de que su tarea constituía una ocasión privilegiada para comprender los textos en sus implicaciones más sutiles. Puesto que han sido capaces de mantener un diálogo intensivo con las opciones terminológicas que permitían verter los conceptos de un modo uniforme, han proporcionado a la traducción española la notable cualidad de armonización y homogenización.

Sin embargo, la edición española no se limita solo a ofrecer al lector los instrumentos necesarios para profundizar en su enfoque de los textos; permite, asimismo, deslegitimar las más diversas publicaciones de los escritos del filósofo, de manera que las antologías, los breviarios, las antologías de citas y las colecciones aleatorias de ciertos pasajes pierden su derecho a existir. Al recusar los intentos de recorte arbitrario de su obra, que en general no veían otra cosa que la satisfacción de intereses inmediatos, ella se impone como un antídoto contra las injusticias cometidas contra su pensamiento.

Puesto que permite considerar el corpus nietzscheano en su integridad, esta edición nos permite ver que hay que tratar de manera diferenciada los textos que el propio filósofo publicó, o bien las anotaciones inéditas que dejó en legado. Además, en el caso del conjunto de fragmentos póstumos, muestra que es preciso distinguir entre escritos preparatorios, variantes, proyectos abandonados, esbozos, notas de lectura, paráfrasis, citas, etc. En consecuencia, esta edición se convierte en una herramienta valiosa para la exégesis meticulosa y precisa de los textos nietzscheanos. Invita al lector a escuchar al autor de Zaratustra, evitando que sus preferencias y sus opiniones se interpongan. Promueve el respeto por los escritos, de manera que no sean reducidos a una intuición primera, o retrotraídos a una causa inteligible que le sea ajena. A fin de cuentas, anima a no considerarlas poniéndonos en lugar de un médico, de un confesor o de un padre espiritual. Permite tener una comprensión más profunda de los textos de Nietzsche, en la medida en que uno se deja guiar por el autor.

Ahora bien, debemos subrayar que la empresa española persigue ante todo el objetivo de elaborar una edición crítica del corpus nietzscheano. En este sentido, se propone, por un lado, aportar las informaciones necesarias con respecto a la clarificación del texto, por el otro, hacerlas preceder de las correspondientes presentaciones con vistas a su contextualización. Cada uno de los cuatro volúmenes que conforman la edición de las Obras completas incluye una introducción general escrita por Diego Sánchez Meca, que se dedica al análisis de la evolución del pensamiento de Nietzsche, así como unos prefacios a los libros o grupos de tex- 
tos elaborados por sus traductores, que se ocupan sobre todo de su surgimiento. Por último, debe destacarse que el primer volumen contiene, además, un apéndice que recoge elementos sobre la polémica en torno a El nacimiento de la tragedia.

Por su parte, la edición de los Fragmentos póstumos incluye también una introducción general firmada por su director, Diego Sánchez Meca, quien, además de indicar los criterios adoptados en dicha publicación, trata de rastrear las líneas generales del pensamiento nietzscheano. Asimismo, contiene introducciones a cada uno de sus cuatro volúmenes firmadas por sus traductores, que intentan recuperar las ideas centrales ahí presentes.

Otro aspecto destacable se encuentra dentro de los «Complementos al conjunto de la edición castellana de las Obras completas y de los Fragmentos póstumos de Nietzsche», situados en el cuatro volumen de las Obras completas. Además de proporcionar al lector un índice de conceptos y de nombres propios presentes en los escritos del filósofo, así como informaciones sobre los instrumentos de trabajo para abordarlos, estos complementos ofrecen importantes clarificaciones sobre la recepción de su obra a lo largo de la historia de sus ediciones. Es sabido que Nietzsche siempre estuvo preocupado por la recepción de su pensamiento. Más que ningún otro filósofo, dio indicaciones a sus lectores sobre la manera en que él esperaba ser leído. De hecho, la historia de la recepción de sus ideas a través de las diferentes ediciones de su obra permite combatir los prejuicios, las creencias y las convicciones que se han dado durante décadas; este trabajo hace posible la deconstrucción de las imágenes más variadas que a lo largo del tiempo se han asociado al nombre de Nietzsche.

La edición crítica de las Obras completas y de los Fragmentos póstumos de Nietzsche publicada en España invita al investigador a reconstruir su itinerario intelectual. Permite rastrear la génesis de sus conceptos y de comprender mejor las etapas de elaboración de sus ideas. En consecuencia, posibilitan una mejor contextualización tanto de sus conceptos como de sus ideas, al tener en cuenta el lugar que ocupan dentro de sus textos. Para ello, como es evidente, no es suficiente con tener simplemente datos biográficos, porque estos son insuficientes para aclarar su obra; tampoco lo es el conocer solamente los temas tratados, porque a veces estos se reparten a lo largo de buena parte de sus textos. Hace falta, más bien, considerar los puntos de referencia teóricos que él adopta, exactamente igual que las diferentes apropiaciones que hace durante las dos décadas que dedica a su actividad intelectual.

Al dedicarse a esta tarea, el investigador deberá enfrentarse a una serie de cuestiones, entre las cuales figura la de la unidad o discontinuidad de la obra de Nietzsche. Es solo de una manera progresiva que él explicita el modo en que concibe su empresa filosófica ${ }^{7}$. Pero si para ello uno no arriesga la inclusión de momentos de ruptura en su pensamiento, esto impedirá ver que haya cambios destacables. Afirmar que su filosofía consiste en la explicitación progresiva de sus ideas no equivale a sostener que sus ideas no estén sujetas a modificación alguna. Por tanto, siguiendo este mismo razonamiento, establecer determinados parámetros para ubicar el surgimiento de sus conceptos fundamentales y detectar

7. Sobre este punto, secundamos la posición de W. Kaufmann, Nietzsche, Philosopher, Psychologist, Antichrist, Princeton, Princeton UP, 1950, sobre todo el capítulo 10. 
las transformaciones que sufren no significa organizar sus escritos en forma de compartimentos estancos que reconozcan, según la costumbre impugnada desde hace tiempo, tres periodos de su obra.

Al pretender clarificar el desarrollo interno de la filosofía de Nietzsche, así como sus líneas de continuidad y sus decisivas transformaciones, la edición española muestra que sus escritos revelan una serie de profundizaciones conceptuales que tienen lugar en momentos claramente delimitados. En este sentido, pone el foco sobre la cuestión de las contradicciones eventualmente presentes en su obra, contradicciones que a menudo han sido invocadas para descalificarla. Puesto que favorece la contextualización de su pensamiento, sirve como defensa contra los malos usos de sus ideas.

Por otro lado, la edición crítica aquí tratada invita al investigador a situar la obra de Nietzsche en el contexto de la historia de la filosofía. Sin recurrir a un marco histórico, difícilmente sería posible una comprensión profundizadora de su pensamiento. Muchos de los equívocos que se han producido y se siguen produciendo en el tratamiento de sus ideas se deben en parte a que no se han tenido en cuenta a sus interlocutores, que por lo general están presentes en sus textos de manera implícita. Preguntarse por aquellos a los que hace referencia implica necesariamente inscribir a Nietzsche dentro de su época, reconstruir el diálogo con sus contemporáneos y sus predecesores, recuperar sus puntos de referencia teóricos, tanto científicos como culturales. Para hacerlo, es imperativo contextualizar el pensamiento nietzscheano no solo en el marco de la historia de la filosofía, sino también en el de la cultura europea. Es imperativo familiarizarse con la historia de Europa, en particular la de Alemania, explorando sus facetas tanto intelectuales como factuales y analizando las ideas y mentalidades. Hacer de Nietzsche un pensador del siglo XIX es aquello que hará posible subrayar el carácter radical e innovador de su reflexión.

Es también a la luz de estas consideraciones como se debe evaluar la edición de las Obras completas y los Fragmentos póstumos publicados en España. Gracias a ella, será posible, sobre todo para los lectores hispanohablantes, leer a Nietzsche sin prevenciones ni prejuicios, sin someterse a posiciones ideológicas o a opciones sectarias; en definitiva, leerlo con la atención y el respeto «como los buenos viejos filólogos leían a su Horacio»8. Para leer a Nietzsche en nietzscheano, además de la filología —que él concibe como «el arte de leer bien»-, es esencial apelar a la historia. Mientras que la lectura filológica permite contextualizar sus escritos en el marco de su obra, considerando el momento en que surgieron, la lectura histórica permite contextualizarlos dentro de la historia del pensamiento europeo.

Después de Mazzino Montinari, la lectura de Nietzsche exige la reconstrucción de su «biblioteca ideal». Al ocuparnos de las numerosas lecturas que realizó, resulta posible identificar las fuentes a las que hace referencia, apropiándose de ellas de un modo ciertamente original. Esta reconstrucción representa una tarea que configuraría, según Montinari, «el complemento de trabajo necesario desarrollado

8. EH, «Por qué escribo libros tan buenos», 5, en OC IV, p. 814. 
junto a la edición, no solo para una comprensión más clara de los textos, sino también para emplazarlos de nuevo en una relación más fructífera con la realidad histórica»?.

En efecto, la publicación del catálogo de la biblioteca de Nietzsche — con la descripción, página a página, de las huellas de lectura identificadas en sus libros, tal como se encuentran hoy día en el Archivo Nietzsche ${ }^{10}$ - ha supuesto una contribución importante para la contextualización de sus textos. Pero también está fuera de duda que la publicación de su correspondencia ha jugado un papel simi$\operatorname{lar}^{11}$. Al estudiar a Nietzsche "como lector», o al considerarlo «como un autor de cartas» en diálogo con las mentes cultivadas de su época, aquellos que se acercan a su pensamiento tienen la ocasión de adentrarse en su universo cultural y, por esta vía, recuperar el estrecho vínculo entre la filosofía y la cultura que nunca dejó de existir en su obra.

Ha sido en perfecta consonancia con las posiciones de Montinari que Luis Enrique de Santiago Guervós se ha encargado de dirigir la edición española de la Correspondencia de Nietzsche. Al hilo de la publicación de sus cartas, tal como fue organizada por Colli y Montinari y sus sucesores ${ }^{12}$, el editor español ha subrayado que este instrumento resulta imprescindible a la hora de tratar los textos nietzscheanos. Además de contribuir a desmitificar la imagen del filósofo y de dar una imagen más precisa de su vida, «nos facilita el conocimiento de la situación cultural y social de la Alemania de la época, la reacción de Nietzsche antes determinados acontecimientos, la relación con su entorno, etcétera» ${ }^{13}$.

Sacar a la luz la relación entre el texto filosófico y aquello que es exterior a él no implica necesariamente reducirlo a los elementos que le son externos, más bien al contrario; llevada a cabo con probidad y rigor, semejante tarea otorga al texto filosófico toda su especificidad. Eso es precisamente lo que nos muestra la edición española de la Correspondencia. Agrupada en seis volúmenes, que presentan la misma estructura, ella se compone primero de una introducción que aspira a contextualizar su actividad epistolar, recuperando para ello los datos de orden biográfico e institucional. Asimismo, contiene una serie de apéndices, que ofrecen también valiosas indicaciones sobre los destinatarios de las cartas enviadas por Nietzsche, los lugares allí mencionados, así como el surgimiento intelectual de sus composiciones musicales. Debe subrayarse que la elaboración de la introducción y de los apéndices es el resultado de un importante trabajo de investigación por parte de los traductores de cada uno de los volúmenes.

Recogiendo las posteriores correcciones editoriales (Nachberichte) de la edición alemana, la publicación en español de la Correspondencia de Nietzsche las

9. G. Campioni y A. Venturelli (eds.), «Introduzione», en La «biblioteca ideale» de Nietzsche, Napoli: Guida, 1992, pp. 8-9.

10. G. Campioni, P. D’Iorio, M. C. Fornari, F. Fronterotta, A. Orsucci y R. Müller-Buck (eds.), Nietzsches persönliche Bibliothek, Berlin: Walter de Gruyter, 2003.

11. Sobre el trabajo previo de la edición crítica de la correspondencia de Nietzsche, cf. M. Montinari, «Nietzsches Briefwechsel. Kritische Gesamtausgabe»: Nietzsche-Studien 4 (1975), pp. 374-431.

12. Cf. Sämtliche Briefe. Kritische Studienausgabe (KSB), 6 vols., Berlin: Walter de Gruyer, 1986, así como Briefwechsel. Kritische Gesamtausgabe (KGB), 25 vols., Berlin: Walter de Gruyter, 1975-2004, que fue inicialmente organizada por Colli y Montinari y completada por Norbert Miller y Annemarie Pieper.

13. L. E. de Santiago Guervós, «Presentación de la edición española», en CO I, p. 15. 
integra en numerosas notas, que aportan importantes aclaraciones, por un lado, sobre acontecimientos, personas y obras a los que el filósofo hace referencia en sus cartas, y, por el otro, sobre el estado de los manuscritos, la revisión de los textos, las fechas y su orden cronológico. En las notas están incluidas, asimismo, las referencias a otras misivas de Nietzsche e información sobre la biblioteca conservada en el Archivo en Weimar.

Habría que añadir que la edición española incorpora, además, una sección que reúne una serie de cartas del pensador que hasta hoy no habían sido traducidas del alemán. Se publican las cartas de Nietzsche y no la de aquellos a las que estaban destinadas, y también contiene, en uno de sus volúmenes, una recopilación de misivas dirigidas a su hermana entre 1880-1884. Puesto que dichas misivas solo han sido conservadas en la transcripción de Elisabeth, su autenticidad ya no es fiable. Sin embargo, en la medida en que probablemente fueron elaboradas a partir de los textos originales, su publicación está plenamente justificada ${ }^{14}$.

Por lo demás, estas decisiones editoriales no hacen más que enriquecer la edición crítica de la Correspondencia de Nietzsche publicada en España. Es bien sabido que muchas cartas del filósofo desaparecieron, como aquellas dirigidas a Heinrich Romundt; otras fueron destruidas, en particular aquellas que había dirigido a Cosima Wagner entre mayo de 1868 y diciembre de 1874. Esto nos lleva a subrayar que es precisamente el afán de hacer pública la actividad epistolar en su integridad lo que constituye el rasgo distintivo de la edición española.

No podemos dejar de destacar que ha sido con la misma determinación con la que Luis Enrique de Santiago Guervós ha emprendido la edición de las cartas de Cosima Wagner al autor de Zaratustra. Además de las misivas que le dirigió entre mayo de 1869 y octubre de 1877, Cartas a Friedrich Nietzsche. Diarios y otros testimonios ${ }^{15}$ reúne un cierto número de aquellas que dirigió a diferentes destinatarios y en las que se hacía referencia al filósofo después de su muerte. Con una estructura similar a la de los volúmenes de la Correspondencia de Nietzsche, este libro incluye también una introducción que reconstruye el contexto de su relación con Richard Wagner y, en particular, con Cosima Wagner. Finalmente, este cuadro lo completan extractos de los Tagebücher ${ }^{16}$ de quien consideró como su «Ariadna».

En definitiva, estamos en condiciones de afirmar que, gracias al trabajo de Santiago Guervós y del equipo de traductores que han participado en este magnífico proyecto, el lector tendrá ocasión de profundizar en sus conocimientos de la vida y de la obra de Friedrich Nietzsche a partir de las relaciones que mantuvo con sus contemporáneos.

\section{III}

Los elementos aquí presentados permiten afirmar, sin lugar a dudas, que esta edición será de importancia capital para hacer progresar los estudios nietzscheanos

14. Sobre este punto, cf. M. Parmeggiani, «Observaciones sobre la traducción», $\mathrm{y}$ «Anexo», en CO IV, pp. 48 y 577.

15. C. Wagner, Cartas a Friedrich Nietzsche. Diarios y otros testimonios, Madrid, Trotta, 2013.

16. C. Wagner, Die Tagebücher, ed. y comentario de M. Gregor-Dellin y D. Mack, 2 vols., Zürich/München: Piper, 1976-1977. 
en todos los ámbitos de la lengua española. En la medida en que quiera separar el trigo de la paja, el investigador que se dedique a la filosofía de Nietzsche estará en condiciones de establecer un diálogo o, más bien, de batirse en duelo con su pensamiento. Consciente de que hay lecturas plausibles y otras que son inapropiadas, él planteará ciertamente la cuestión de si su lectura no ha estado contaminada por el dogmatismo que turbia tantas otras lecturas. ¿Será también la suya propia dominada por una insidiosa voluntad de verdad?

Al perseguir el objetivo de ofrecer a los lectores hispanohablantes un acceso a los escritos de Nietzsche que todavía no habían sido traducidos, la edición española de las Obras completas, de los Fragmentos póstumos y de la Correspondencia de Nietzsche espera contribuir a la mejor comprensión de su pensamiento. Pero el hecho de que no solo se limite a publicarlos, sino también a realizar todo un trabajo con vistas a su contextualización, hace que su contribución traspase sin duda las fronteras de España y de Europa.

[Traducción de Kilian Lavernia] 